\title{
Synthesis of Poly(oxyethylene)-Poly(Z-L-lysine) Hybrid Graft
}

\section{Copolymers}

\author{
Ivaylo V. Dimitrov* ${ }^{*}$, Iliyana V. Berlinova ${ }^{\dagger}$, Nikolay G. Vladimirov ${ }^{\ddagger}$ \\ ${ }^{\dagger}$ Institute of Polymers, Bulgarian Academy of Sciences, Sofia 1113, Bulgaria, \\ ${ }^{\ddagger}$ Hercules Incorporated, Research Center, Wilmington, Delaware, 19808-1599, USA
}

\section{Supporting Information}

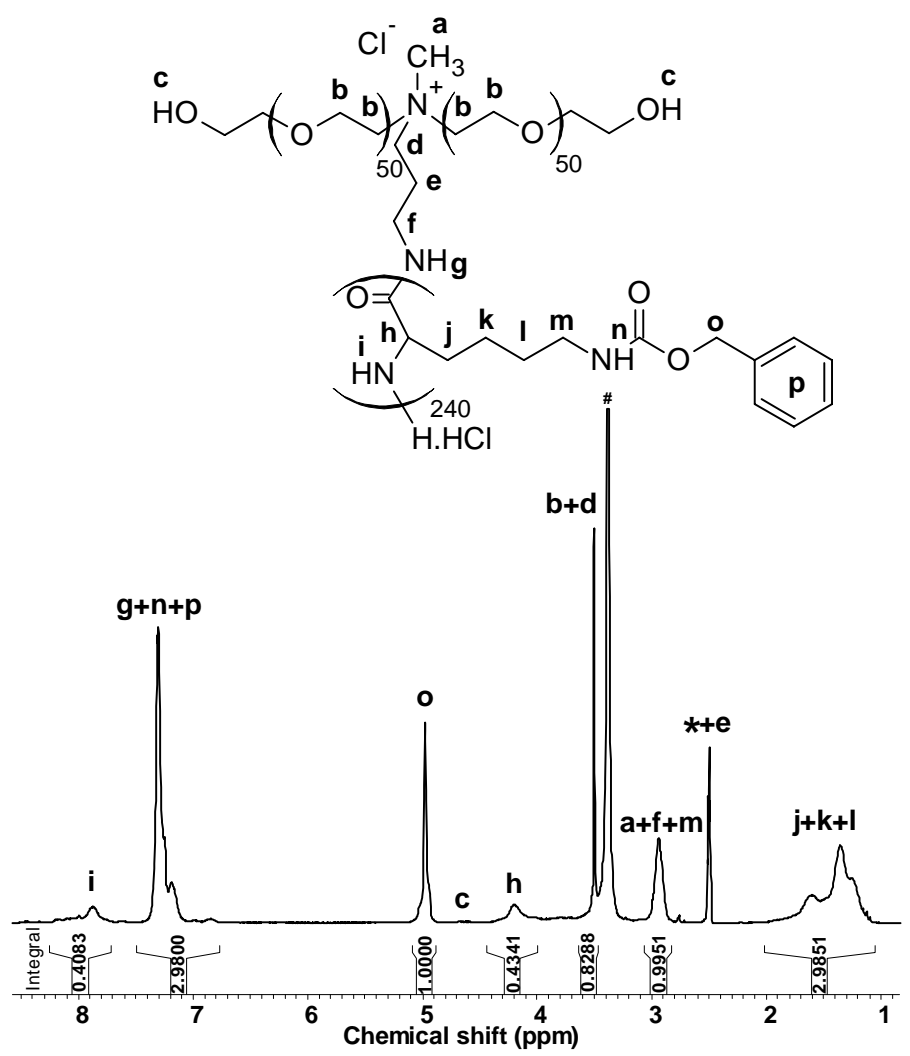

Figure S1. ${ }^{1} \mathrm{H}$ NMR (250 MHz) spectrum of the Y-shaped block copolymer HY2 in dimethylsulfoxide$\mathrm{d}_{6}$ at $25^{\circ} \mathrm{C}$ (*dimethylsulfoxide, ${ }^{*}$ water $)$. 


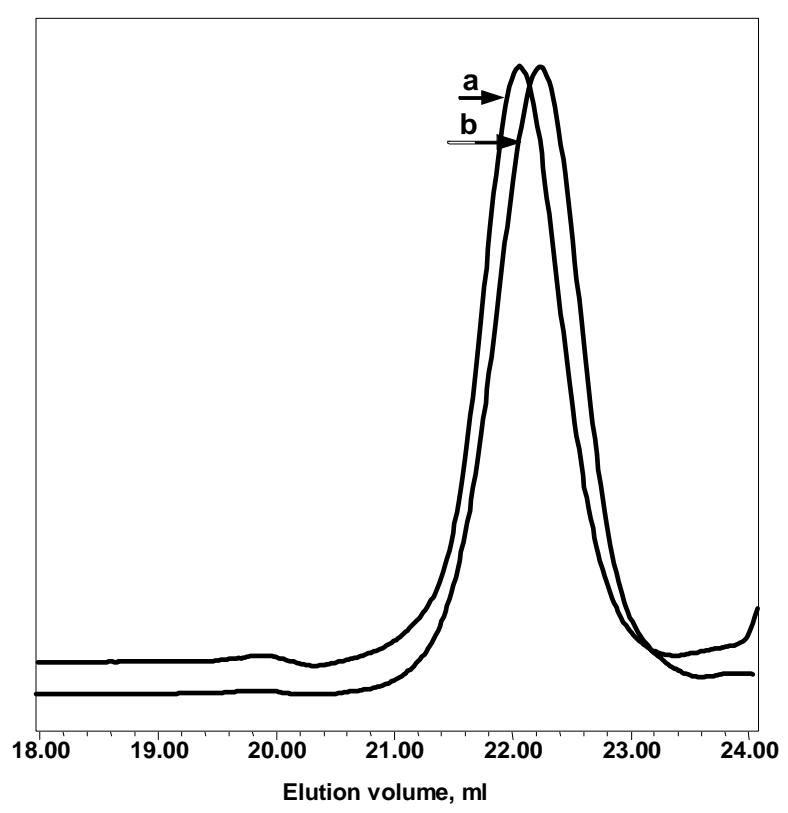

Figure S2. Gel permeation chromatograms in $N, N$-dimethylacetamide $(+0.5$ wt. $\% \mathrm{LiCl})$ at $50^{\circ} \mathrm{C}$ of: a) the poly(oxyethylene) precursor $\mathrm{E}_{50} \mathrm{NE}_{50}\left(M_{\mathrm{n}}=2700, M_{\mathrm{w}} / M_{\mathrm{n}}=1.29\right)$; b) the Y-shaped block copolymer HY2 $\left(M_{\mathrm{n}}=2100, M_{\mathrm{w}} / M_{\mathrm{n}}=1.47\right)$. The GPC data were obtained relative to PEO standards. 